\title{
EARLY THYMOQUINONE INJECTIONS AND EXPRESSION OF DNA REPAIR ENZYMES IN HAMSTER BUCCAL POUCH-INDUCED DYSPLASIA
}

\author{
Rania Hanafi *
}

\begin{abstract}
Because carcinogenesis is a multi-step process, Sporn (1976) suggested that the best time to control cancer is in its "preneoplastic" phase, before it has a chance to develop into "invasive" cancer. Therefore, the aim of the present work was to evaluate the effect of TQ on the dysplasia induced in that model, through IHC expression of both enzymes.6 weeks of DMBA painting resulted in irreversible genetic changes that did not resolve by the studied repair enzymes. So it can be proposed that TQ had resulted in regression of the carcinogenesis process through the following mechanisms. First: TQ as a potent antioxidant that antagonizes the adverse effect resulting from elevated ROS levels due to carcinogenesis i.e. reduction of the intracellular ROS allowed the repair enzymes to fulfill their main target.Second: TQ through inactivation of the TNF-Nf- $x$ B pathway, and in turn induced p53 activation, i.e. stimulated apoptosis of malignant cells. Third: TQ has the ability to arrest cells at different phases of the cell cycle leading to growth inhibition, so allowing repair of mutated cells
\end{abstract}

KEYWORDS: DMBA dysplasia model, XRRC1-, and ERRC1- repair enzymes, Thymoquinone.

\section{INTRODUCTION}

Introduction: The experimental oral carcinogenesis model, invented by Salley (1954), ${ }^{(\mathbf{1})}$ had gained much interest as it mimics biologically the proposed sequence of human oral cancer. It was used to study the carcinogenesis process, prevention and treatment of oral cancer. ${ }^{(2-4)}$ Dimethylbenza-a-anthracene (DMBA) is one of the polycyclic hydrocarbons (PAHs), which are environmental carcinogens as products of incomplete fuel combustion (in air), water, soil, food supply, cigarette smoke and alcohol. ${ }^{(5,6)}$ When DMBA is painted to the hamster buccal pouch (HBP) for 6 weeks $(0.5 \%$ in mineral oil, 3/week) it results in epithelial dysplasia, ${ }^{(3)}$ while for 12-14 weeks it results in invasive well differentiated squamous cell carcinoma (SCC). ${ }^{(2)}$ Chemotherapy was the classic approach for cancer treatment, while recently phytochemicals are the main target for cancer prevention and treatment, as they are more safe, efficient and economic. ${ }^{(7)}$ One of these phytochemicals is TQ that is currently in use for chemoprevention ${ }^{(8)}$ and chemotherapy. ${ }^{(9-11)}$

\footnotetext{
* Associate Professor of Oral Pathology, Faculty of Dentistry, Suez Canal University, EGYPT
} 
Thymoquinone (TQ) (2-isopropyl-5-methylbenzo-1, 4-quinone) is the most abundant constituent and biologically active compound of Nigella sativa (NS) oil. ${ }^{(12)}$ For years, in vivo and in vitro researches proved a promising anticancer effect of TQ, with no toxic effect to normal tissues. ${ }^{(10)} \mathrm{TQ}$ is a potent antioxidant, due to its scavenging activity against several reactive oxygen species (ROS). ${ }^{(13)} \mathrm{TQ}$ anti-inflammatory activity was proved in experimental models and considered a clinically-viable agent against a variety of inflammatory conditions. The hallmark of this carcinogenesis (HBP/DMBA) model depends on the chronic inflammation induced by continuous DMBA application. ${ }^{(2)}$ Necrosis and shortening of the painted pouches was a constant finding following the early DMBA paintings. ${ }^{(14-16)}$ Clinical and epidemiologic studies had linked chronic inflammation with cancer development, mostly through TNF-Nf- $x$ B pathway. Nf- $x \mathrm{~B}$ chronic activation can cause DNA damage and increase cell proliferation, as well as increase the probability of cells to further acquired oncogenic DNA mutations (through ROS and RNS production). ${ }^{(17)}$ On the other hand the NF- $x \mathrm{~B} 2$ gene and its transcription factors have an essential role in inflammation, in turn playing a critical part in many steps of cancer initiation and progression ${ }^{(18)}$. TQ was found to suppress this inflammatory state through inhibition of Nf- $\varkappa \mathrm{B} .{ }^{(4,14)}$

It is estimated that approximately $10^{13}$ cells within the human body incurs tens of thousands of DNAdamaging events per day, due to both endogenous and exogenous factors. ${ }^{(19)}$ Regardless of the type of damage and required mechanism for repair, cells initiate a highly coordinated cascade of eventscollectively known as the DNA damage response (DDR) that senses the DNA damage, signals its presence, and mediates its repair. ${ }^{(20,21)}$ Deficiency of DNA repair proteins in normal conditions results in cell death, however, accumulated damages in the unrepaired cells results in genomic instability that ultimately leads to carcinogenesis. ${ }^{(22)}$

In human head and neck cancer (HHNC), the most prevalent mutations are repaired by XRCC1, (23) and ERCC1. ${ }^{(24-26)}$
A significant correlation was observed between excision repair cross-complementing 1 (ERCC1) and $\mathrm{x}$-ray repair cross complementing 1 (XRCC1) expression in bladder tumors ${ }^{(27)}$ with a significant association between ERCC1 expression and the prognosis of lung, ${ }^{(28)}$ upper gastrointestinal ${ }^{(29)}$ and head and neck cancer patients. ${ }^{(30)}$

Curioni et al. (2013), linked XRCC1-194Trp polymorphism and increased risk of human OSSC. They noted that XRCC1 gene polymorphisms have been linked to reduced capacity for removal of DNA damage. ${ }^{(31)}$

ERCC1 has a rate-limiting role in the nucleotide excision repair (NER) pathway, ${ }^{(32)}$ and emerged as a prognostic marker in lung ${ }^{(28)}$ and head and neck cancers. ${ }^{(30)}$

Patients positive for ERCC1, XRCC1 and either ERCC1 or XRCC1, exhibited significantly improved disease-specific survival rates. ${ }^{27}$ Both ERCC1 and XRCC1 expressions were found useful as independent prognostic markers for survival in bladder cancer patients receiving combined trimodality therapy. (27) Although ERCC1 and $\mathrm{XRCC} 1$ are not involved in the same DNA repair pathway, both genes are located in close proximity to each other at $19 \mathrm{q} 13.2-13.3,{ }^{(33)}$ and they may be simultaneously activated or altered by deletion and other changes as well. This fact (in humans) would be expected to work with the present hamster model, due to the reported importance of XRCC1 protein in rodents. XRCC1-deficient mouse or hamster cells were hypersensitive to DNA damaging agents generating single strand breaks (SSBs) and display genetic instability after such DNA damage. ${ }^{(34)}$

Because carcinogenesis is a multi-step process, Sporn (1976) $\left({ }^{35)}\right.$ suggested that the best time to control cancer is in its "preneoplastic" phase, before it has a chance to develop into "invasive" cancer. Therefore, the aim of the present work was to evaluate the effect of TQ on the dysplasia induced in that model, through IHC expression of both enzymes. 


\section{MATERIAL AND METHODS}

This work followed the classic hamster buccal pouch/ dimethylbenz-[a]-anthracene (HBP/DMBA) oral epithelial dysplasia (OED)-induction model, followed by few thymoquinone (TQ) i.p. injections as a promising therapeutic agent, through expression of 2 DNA repair enzymes. The experiment was held at the animal house, Faculty of Dentistry, Suez Canal University, Ismailia, Egypt. The study was carried out using 24 male golden Syrian hamsters (Mesocricetus auratus), weighing 80-100 grams. They were kept 6 animals / cage $(40 \mathrm{~cm} \times 50 \mathrm{~cm})$, divided as follows: Group A: Six animals served as the negative control group (untreated group), they were euthanized at day zero. Group B: (positive control) six animals were painted with DMBA on the left pouches 3 times/ week / 6 weeks, then were euthanized after 6 weeks. Group C: 12 animals were painted with DMBA as in group $\mathrm{B}$, then sub-divided into TQ-treated groups as follows:

C1: 6 animals were intraperitoneally (ip) injected four times (day after day) with TQ $(0.1 \mathrm{mg} / \mathrm{kg}$ body weight). C2: 6 animals were ip injected 6 times (day after day) with TQ as before, then both $\mathrm{C} 1$ and $\mathrm{C} 2$ animals were euthanized after 6 weeks.

*Thymoquinone powder $(\mathrm{C} 10 \mathrm{H} 12 \mathrm{O} 2)$ [cat\# 490-91-5] was dissolved in propylene glycol (C3H8O2) [cat\# 57-55-6] to get $0.1 \mathrm{mg} / \mathrm{kg}$ body weight concentration of thymoquinone solution. *The chemical carcinogen 7, 12 Dimethylbenz[a]-anthracene (DMBA) powder [cat\# D3254], was dissolved in heavy mineral oil [cat\# M 3516] to get a $0.5 \%$ DMBA solution.

* All previous chemicals were purchased from Sigma Chemicals Company, USA.

** XRCC1 antibody (mouse monoclonal) [cat\# GTX23133] and ERCC1 antibody (mouse monoclonal) [cat\# GTX22356] were purchased from Genetex Incorporation, California, USA.

Euthanization was done by inhalation of ether (soaked cotton piece), in a tightly closed container.
Both pouches of all groups were excised, and processed for both H\&E and IHC staining for the DNA repair enzymes. Three slides were prepared from each pouch, for light microscopic evaluation.

*Grading of epithelial dysplasia was carried out according to El-Dakhakhny et al (2009) ${ }^{[3]}$

*Immuonohistochemical (IHC) evaluation: (The steps of IHC followed the manufacturer's instructions).

From each paraffin block three sections ( $4 \mu \mathrm{m}$ in thickness) were mounted on positively-charged slides. The antibodies used were Anti-XRCC1, and Anti-ERCC1. Nuclear staining was considered as the expression of activated genes, i.e. immunepostive.

* Photos: All images were captured using digital camera (C5060, Olympus, Japan) mounted on a light microscope (BX60, Olympus, Japan). Images were then transferred to the computer system, for analysis in the Precision Measurement Unit, Department of Oral Pathology, Faculty of Dentistry, Ain Shams University. The immunohistochemical analysis was performed using Image $\mathrm{J}, 1.41 \mathrm{a}$, (NIH, USA) image analysis software. For each case, the area fraction of immunopositivity for at least four different microscopic fields was measured. The mean of area fraction (MAF) for each case was then calculated by adding the area fractions of the four fields and dividing the result by four. The total of MAF was then calculated and used for statistical analysis. ${ }^{(57)}$

\section{Statistical analysis:}

Data was tabulated and displayed as MAF and standard deviations then analyzed using SPSS version 20. ANOVA test was done to compare between the MAF differences of different groups. Post hoc LSD test was performed for pairwise comparison. The $\mathrm{P}$ value was considered significant if its value was less than or equal to 0.05 . 


\section{RESULTS}

\section{Gross examination:}

Group A "Negative control": the hamsters showed no gross changes. After euthanization, the buccal pouches' lengths were about $5 \mathrm{~cm}$ for all hamsters, as well as the right pouches of all experiment groups (Fig. 1a).

Group B: "Positive control" (DMBA-painted left pouches). The animals were debilitated. Necrotic whitish debri were coming out with the brush from the third painting and disappeared one week later, indicating necrosis of the distal end. This was followed by marked perioral hair loss, up to the abdomen in some animals. Skin ulcers or abscesses were seen mainly at areas of hair loss. The excised painted pouches were about $2 \mathrm{~cm}$ in length, reddish in color with areas of ulceration, and exophytic lesions (Fig.1b).

Groups $\mathrm{C} 1$ and $\mathrm{C} 2$ \{Hamsters painted and injected 4 and 6 times with TQ, then euthanized after 6 weeks\}, showed much improvement in the animals' general health. All pouches' lengths were approximately $3-4.5 \mathrm{~cm}$ and were normal appearing, i.e. no redness / ulcerations, and only remains of exophytic lesions (Fig.1 c and d).

\section{Histopathological (H\&E) \& immunohistochemi- cal (IHC) results: H\&E:}

Group A: The pouches of negative control group and right (unpainted) pouches of the experimental groups, showed normal appearing mucosa (except for slight hyperkeratinization). They showed thin keratinized stratified squamous epithelium, covering collagenous lamina propria, thin muscle fibers layer (Fig.2a). IHC: group A (and unpainted pouches of the experimental groups), revealed diffuse intense expression of XRCC1 and ERCC1, in all nucleated layers (Fig. 2b and 2c).

\section{Positive control:}

H\&E (6 wks of DMBA only): The painted pouches showed large positive control necrotic areas at the distal part, and multiple ulcerated

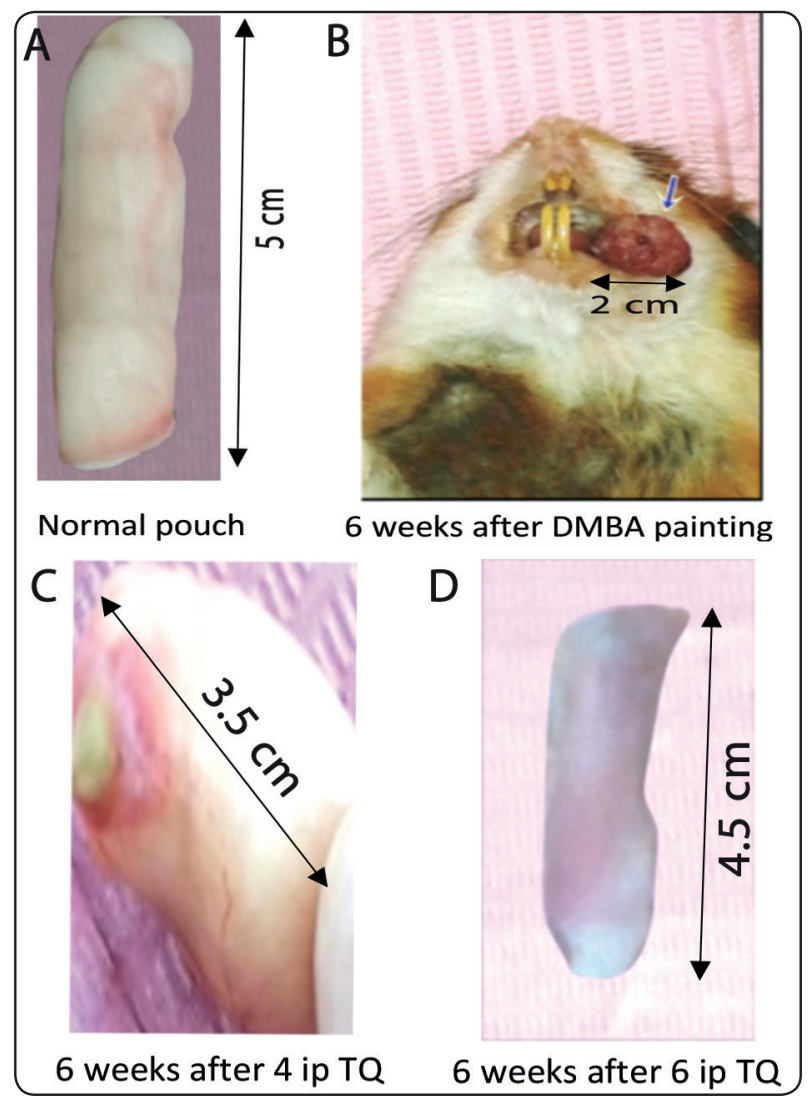

Fig. (1) Showing gross pouches of all groups: (a) a pouch from unpainted pouches 'group, length is about $5-6 \mathrm{~cm}$. (b) a pouch from positive control group (DMBA) length is about $2-2.5 \mathrm{~cm}$. (c) a pouch from group $\mathrm{C} 1$, length is about $3-3.5 \mathrm{~cm}$. (d) a pouch from group $\mathrm{C} 2$, the length is about $4.5 \mathrm{~cm}$.

areas along the pouches' length. Well differentiated carcinomas and superficial invading islands were noticed histologically in the focal areas. (Fig 3a). The rest of the epithelial lining was disturbed with variable degrees of dysplasia (Fig.3b). IHC: group B revealed low MAF of XRCC1 and ERCC1 (Fig. $3 \mathrm{c}$ and $\mathrm{d}$ ). The nuclear reaction was scattered within the lesions and along the epithelial lining.

Group C: C1: DMBA-painted, followed by 4 i.p TQ injections. H\&E examination revealed focal areas of mild/ moderate dysplastic areas along the rest of epithelial lining (Fig. 4a, and b)IHC: revealed scattered cells with positive nuclear stain for XRCC1 and ERCC1 along the epithelial lining (Fig.4c, and d). 


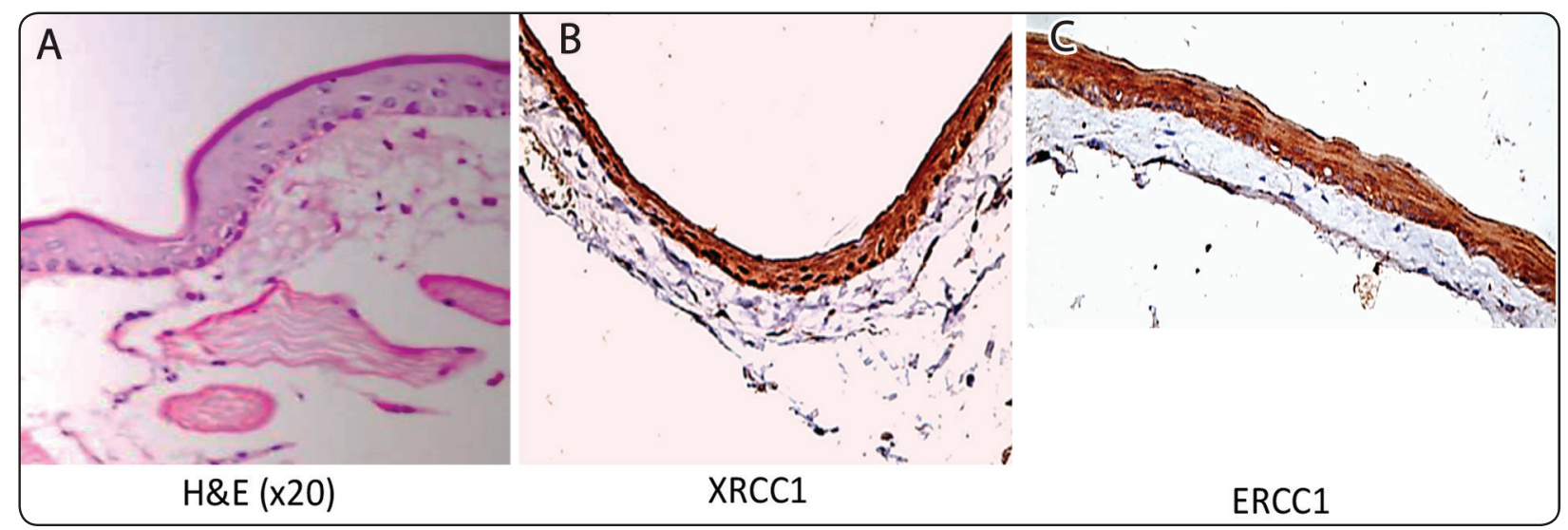

Fig. (2): Showing normal appearance of unpainted-DMBA pouches of all groups. (a) H\&E section showing thin keratinized stratified squamous epithelium covering non inflamed collagenous lamina propria, and a thin layer of striated muscle fibers (x 20). (b) XRCC1 stained section of unpainted pouch, showing intense diffuse (nuclear and cytoplasmic) reaction for the surface epithelium (XRCC1 IHC stain x20). (c) ERCC 1-stained section for unpainted pouch, showing comparable diffuse reaction as XRCC1 reaction, for the surface epithelium (ERCC 1 IHC stain x20).

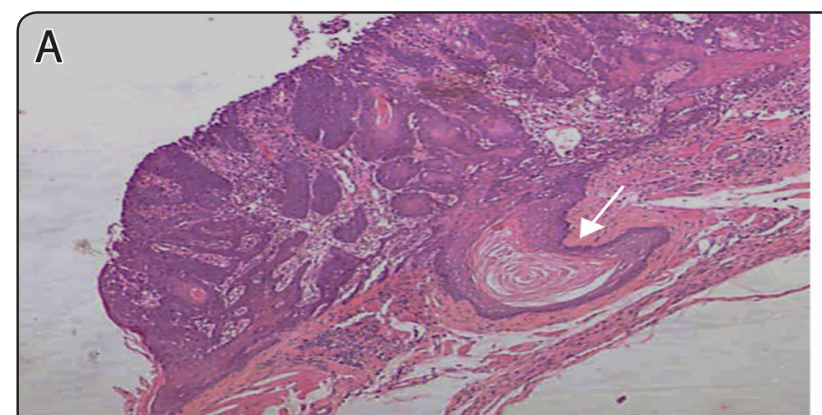

Focal areas with invasion (arrow)

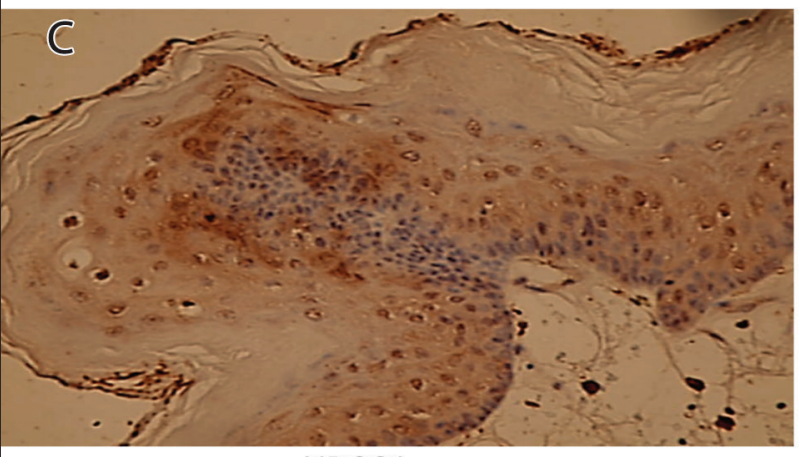

XRCC1

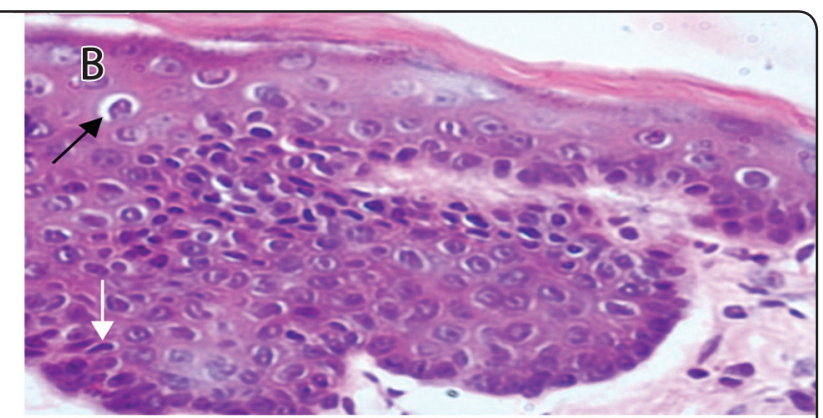

Basal cell hyperplasia (white arrow), drop shape rete ridges, hyperchromatism, cellular and nuclear pleomorphism, and prominent nuclei yours (black arrow).

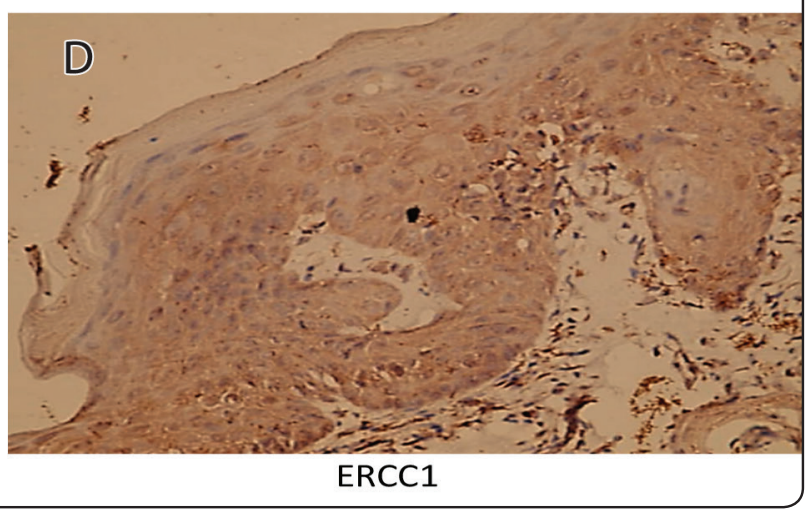

Fig. (4): Representative histologic sections from pouches of group C1. (a and b): H\&E sections showing focal areas of mild/ moderate epithelial dysplasia with no inflammatory cells in the lamina propria (H\&E x40 and 20, respectively). (c): XRCC1-stained section from a pouch in group C1, showing positive immune reaction (XRCC1 IHC X40). (d): ERRC1stained section from a pouch in group $\mathrm{C} 1$, showing positive immune reaction (ERRC1 IHC x 40). 
C2: DMBA-painted followed by 6 i.p TQ injections. H\&E: revealed hyperplastic and hyperkeratinized stratified squamous epithelium with focal areas of mild dysplasia. The rest of the epithelial lining is normal appearing (Fig. 5a, and b). IHC: The reaction was mainly in the lower epithelial layers, with scattered distribution along the epithelial lining (Fig. 5c, and d).

\section{Statistical results of the immune expression of both enzymes: (Tables 1-4)}

The mean area fraction (MAF) in group $\mathrm{C} 1$ was not statistically significant than the positive control group (B). Whereas in group $\mathrm{C} 2$, the MAF of XRCC1 and ERCC1 was only statistically significant as compared to group $\mathrm{A}$, while between group B and C1 was not statistically significant.

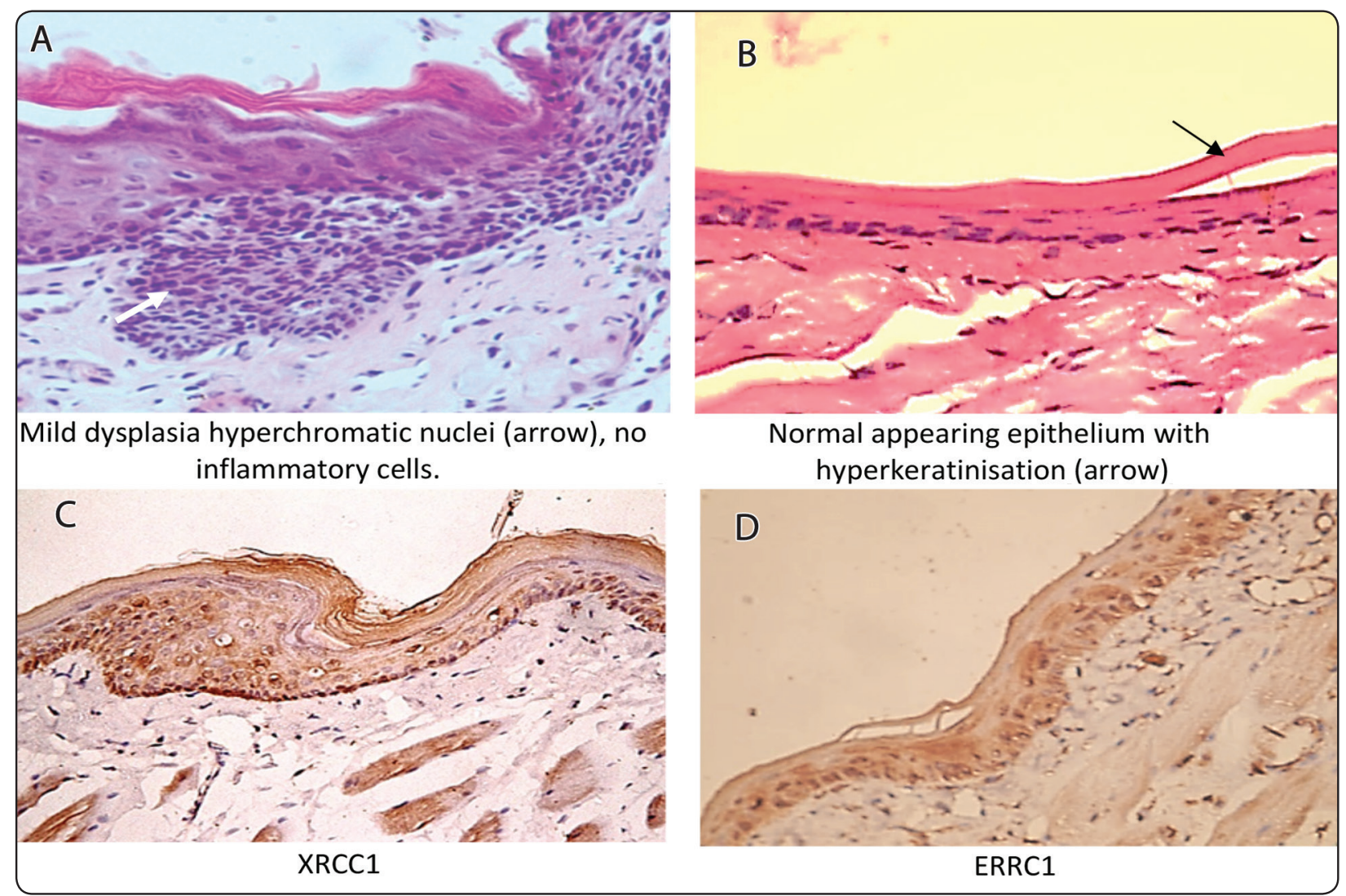

Fig. 5: Histopathologic sections from pouches in group C2. (a and b): H\&E sections showing focal areas of mild dysplasia (a), and the rest of the lining is normal appearing epithelium (b), with no inflammatory cells in the lamina propria (H\&E x40). (c): XRCC1-stained section from a pouch in group C2, showing positive immune reaction (XRCC1 IHC x40). (d): ERRC1stained section from a pouch in group C2, showing positive immune reaction (ERRC1 IHC x 40). 
TABLE (I): Showing the comparison between the MAF values of the four groups (XRCC 1):

\begin{tabular}{|c|c|c|}
\hline Group & MAF & $\begin{array}{c}\text { Standard } \\
\text { deviation }\end{array}$ \\
\hline Negative control (A) & 115.11 & 68.09 \\
\hline C1 (4 ip TQ) & 73.93 & 28.64 \\
\hline C2 (6 ip TQ) & 35.93 & 2.21 \\
\hline Positive control (B) (DMBA) & 53.69 & 21.39 \\
\hline F value (P value) & \multicolumn{2}{|c|}{$122.31(0.03)^{*}$} \\
\hline
\end{tabular}

TABLE (II): Showing pairwise comparisons between groups using LSD post hoc test for XRCC 1:

\begin{tabular}{|c|c|c|c|}
\hline Group & Compared to & MAF difference & Significance \\
\hline A & C1 & 41.18 & 0.23 \\
\hline & C2 & 79.18 & $0.036^{(*)}$ \\
\hline C1 & B & 61.42 & 0.086 \\
\hline & C2 & -41.18 & 0.23 \\
\hline & B & 38.00 & 0.26 \\
\hline C2 & A & 79.24 & 0.54 \\
\hline & C1 & -38.00 & $0.036 *$ \\
\hline & B & -17.76 & 0.59 \\
\hline B & A & -61.42 & 0.086 \\
\hline & C1 & -20.24 & 0.54 \\
\hline & C2 & 17.76 & 0.59 \\
\hline
\end{tabular}

The MAF difference is significant at $p \leq 0.05$.

Dependent variable: total of XRCC1
TABLE (III) Showing comparisons between the MAF values of the four groups: total of ERCC1:

\begin{tabular}{|l|l|l|}
\hline Group & MAF & Standard deviation \\
\hline A & 143.06 & 63.58 \\
\hline C1 & 91.25 & 36.32 \\
\hline C2 & 54.20 & 6.42 \\
\hline B & 77.44 & 21.82 \\
\hline F value (P value) & $136.27(0.01)^{*}$ \\
\hline
\end{tabular}

TABLE (IV): Showing pairwise comparisons between groups using LSD post hoc test for ERCC1: Dependent variable: total of ERCC 1

\begin{tabular}{|l|l|l|l|}
\hline Group & Compared to: & MAF difference & Significance \\
\hline A & C1 & 51.81 & 0.136 \\
\hline & C2 & 88.86 & $0.022^{*}$ \\
\hline & B (DMBA) & 65.61 & 0.069 \\
\hline C1 & A & -51.81 & 0.136 \\
\hline & C2 & 37.05 & 0.271 \\
\hline & B & 13.80 & 0.671 \\
\hline C2 & A & -88.86 & $0.022^{*}$ \\
\hline & C1 & -37.05 & 0.271 \\
\hline & B & -23.24 & 0.479 \\
\hline B & A & -65.61 & 0.069 \\
\hline & C1 & -13.80 & 0.671 \\
\hline & C2 & 23.24 & 0.479 \\
\hline
\end{tabular}

The MAF difference is significant at $p \leq 0.05$. 


\section{DISCUSSION}

The present work aimed to report the expression of DNA repair enzymes (XRCC1 and ERCC1) under the influence of early TQ ip injections, for protection against the HBP/DMBA dysplasia-induced model. In human head and neck cancer (HHNC), the most prevalent mutations are repaired by XRCC1 ${ }^{(23)}$ and ERCC1. ${ }^{(24,25)}$ As the HBP / DMBA -induced cancer model mimics HHNC biologically, these enzymes were the target of this study.

$H \& E$ results of the present work revealed normal appearing pouch mucosa of the negative control group, and the right pouches of all experimental groups which showed only hyperkeratinization.

This hyperkeratinization could be due to increased use of these pouches when the left painted pouches were inflamed and reduced in length.

Immunohistochemical (IHC) findings showed high expression of both enzymes (XRCC1 and ERCC1), in all layers (both nuclear and cytoplasmic). This indicates the effectiveness of these enzymes in preserving normal epithelial cells from damage-induced by regular activities of the pouches, as mastication of rough food and their metabolic process. Metabolic reactions release different ROS, among others that damage DNA. Apart from external factors that induce mutations, it was estimated that naturally occurring oxidative DNA damages arise at least 10,000 times per cell / day in humans and 50,000 times or more per cell / day in rats..$^{36,55)}$

The HBP/DMBA carcinoma is induced when DMBA, a pro-carcinogen, becomes carcinogenic after metabolic conversion by cellular enzymes, to electrophilic reactants (diol-epoxides), able to covalently interact with cellular macromolecules, including DNA, to form adducts. ${ }^{(37)}$

Some phytochemicals were found to modulate these metabolic enzymes resulting in aborting the carcinogenesis process, in this model. ${ }^{(38)}$ Casto et el. (2002) found that lyophilized black raspberries caused an inhibition of tumors in hamsters' pouches, believed to be due, in part, to reduction in the formation of DNA adducts that can initiate carcinogenesis. ${ }^{(39)}$

Group B (DMBA for 6 weeks, then euthanized after 6 weeks), showed multiple well differentiated carcinomatous lesions with epithelial disturbance along the rest of epithelial lining with variable dysplastic grades up to carcinoma in situ (CIS). In that model, it was reported that after sustained DMBA painting for 6 weeks, the carcinogenesis process progressed to frank invasive carcinoma. ${ }^{(3)}$

The ERCC1 and XRCC enzymes showed low expression within the scattered cells along the pouch epithelial lining of group B which showed severe dyaplasia and CIS. This result is consistent with Vaezi et al. (2011) ${ }^{(40)}$ who found that both enzymes were expressed at lower levels, in human lung cancer and HHNC cells. As the function of these enzymes is to repair damaged DNA, their lower expression, in the present work, indicates either their mutation by the carcinogen, or the tumor cells' mutation does not involve the type of mutation where these enzymes work upon, or the oxidative stress, associated with the carcinogenesis process, ${ }^{(41)}$ was not relieved by the endogenous anti-oxidant mechanisms. Moreover, this could be due to accumulation of more DNA mutations, i.e. progression from severe dysplasia/ CIS to invasive carcinoma. ${ }^{(35)}$ It is known that cells from aggressive tumors with extensive genomic instability may harbor chromosomal aberrations that result in failure of gene transcription, including DNA repair genes, resulting in lower protein expression of the gene products. ${ }^{(27)}$

This hypothesis could be explained by the study of Shen et al. (1998). ${ }^{(42)}$ They analyzed four XRCC1 mutant cell lines and sequence alterations in the XRCC1 coding region. Their results indicated that each of four mutant lines showed severe reduction in the level of XRCC1 protein. ${ }^{(42)}$ 
Another explanation for reduced expression of both enzymes is that reported by Ratnasinghe et al (2001), where XRCC1 could be subjected to genetic polymorphisms at codons 194, 280, and 399. These polymorphisms occur at residues that are identical in human, hamster, and mouse. ${ }^{(28)}$

The hallmark of this carcinogenesis (HBP/ DMBA) model depends on the chronic inflammation induced by continuous DMBA application, mostly through TNF-Nf-kB pathway.Clinical and epidemiologic studies had linked chronic inflammation with cancer development, mostly through TNF-Nf- $\varkappa$ B pathway. ${ }^{(18,43)}$

TQ was found to suppress this inflammatory state through inhibition of nuclear factor- $\varkappa \mathrm{B}$ (Nf$\varkappa \mathrm{B},{ }^{(4,14]}$ that in turn affects both oncogenes and suppressor genes as $\mathrm{p} 53$, i.e. abort the carcinogenesis process. In a previous study carried out in our Department of Oral Pathology, Faculty of Dentistry, Suez Canal University, TQ alone or in different formulations and concentrations, was found to activate p53, with regression of the carcinogenesis process from invasive carcinoma to mild/moderate dysplasia. ${ }^{(44)}$ Another study using TQ alone or in different formulations and concentrations, during DMBA painting, resulted in negative expression of both TNF- $\alpha$ and Nf- $x \mathrm{~B}$ in inflammatory and epithelial cells in addition to expulsion of the local inflammatory cells outside the surface epithelium. ${ }^{(45)}$ Furthermore, in another study, when one ip injection of TQ following induction of dysplasia, a highly significant elevation of serum TNF- $\alpha$ was recorded from the second day of injection up to two weeks, as compared to negative and positive control groups. (16) Expulsion of local inflammatory cells was also a prominent finding in that work. Both previous studies strengthen the anti-inflammatory effect of TQ, through suppression of the TNF-NF-kB pathway.

In group $\mathrm{C} 1$, in the present work, when $4 \mathrm{TQ}$ ip injections $(0.1 \mathrm{mg} / \mathrm{kg})$ followed induction of dysplasia, the histologic finding ranged from normal appearing to mild/ moderate epithelial dysplasia. That regression of the carcinogenesis process can be explained due to inactivation of the TNF-NF-KB pathway by TQ, and activation of $\mathrm{p} 53,{ }^{(44)}$ to induce apoptosis of mutated cells. It can be also due to its anti-oxidative effect that aborted progression of the carcinogenesis process. In these pouches, the subepithelial area was free of inflammatory cells, mostly due to their expulsion, as reported by Hassan et al.(2017) ${ }^{(45)}$ and Algharyni et al (2019) ${ }^{(16)}$ In that group ( $\mathrm{G} \mathrm{C} 1$ ), the MAF showed higher staining expression of both enzymes, comparable to the DMBA-only group, however, was not statistically significant.

The higher expression of both enzymes after TQ treatment (group $\mathrm{C} 1$ ), with regression to dysplasia rather than carcinomas (group B) could be explained on the findings of Santana et al (2017). They documented that APE-1 and XRCC-1 are overexpressed in oral tongue squamous cell carcinoma (OTSCC) and that XRCC-1 is associated with better clinical staging (early clinical stages I and II, P < $0.01)$. ${ }^{(46)}$

The positive cells were in the lower layers of normal-appearing epithelium. This finding indicates that these cells still carry mutations induced by DMBA, are going to be repaired by both enzymes or could be due to the continuous exposure of the pouches' mucosa to the daily masticatory effect. The late follow-up timing of euthanization (6 weeks post TQ injections), in the present work, would not allow close monitoring of TQ effect on activation of these repair enzymes that one TQ injection might be effective as early as 1-2 days, as reported by Algharyni et al (2019).(16)

The significant MAF difference of expression of XRCC1 and ERCC1 enzymes was achieved in group $\mathrm{Cb}$, (6 ip TQ injections followed induction of dysplasia, and checked after 6 weeks). Numerically, with 6 weeks of DMBA painting, their expression was significantly reduced than their full expression 
in the untreated pouches. With 4 TQ injections the enzymes' expression was elevated above the DMBAonly treated pouches. The significant reduction of their expression after $6 \mathrm{TQ}$ injections indicates that either most mutated cells were repaired by the 4 injections, or TQ had activated $\mathrm{p} 53^{(44)}$ that in turn resulted in apoptosis of most mutated cells.

Another explanation could be due to the hypothesis that XRCC1 is required for at least two types of SSBR (single-strand break repair) processes, a rapid pathway that occurs throughout the cell cycle and a second pathway that is specific for $\mathrm{S} / \mathrm{G} 2 .{ }^{\left({ }^{47}\right)}$ So these +ve cells could be in the $\mathrm{S} / \mathrm{G} 2$ stage of the cell cycle. That group's result ( $\mathrm{G} \mathrm{C} 2)$ was on line with results of Amer, ${ }^{(48)}$ where longer time of TQ-treatment showed the least significant result for both enzymes, in that model. His results were evaluated by IHC and PCR techniques. The author induced squamous cell carcinoma in hamster pouches (12 weeks), followed by topical and ip injections of TQ (o.1 mg/kg body wt.), or TQ loaded on gold nano particles $(0.01 \mathrm{mg} / \mathrm{kg}$ of GNps/ $\mathrm{TQ})$, or (0.001 mg/kg of GNps/TQ) or GNps alone. All groups were treated for 6 and 12 weeks. The pouches painted with DMBA for 12 weeks showed significant reduction of both enzymes' expression as compared to the negative control group, except the group treated with $0.001 \mathrm{mg} / \mathrm{kg}$ GNps/TQ for 12 weeks. The histologic changes showed regression from invasive carcinoma (DMBA-only) to moderate dysplasia. In that study, gold nanoparticles were used as drug carrier ${ }^{(49)}$ that facilitated TQ internalization to cells, as well as the combined topical and systemic routes of administration had accentuated TQ function.

Regarding the proposed anticancer effect of $\mathrm{TQ}$, in the present model, other phytochemicals as coumarin, black raspberry, green tea extract, and the whole Nigella sativa oil showed promising therapeutic effect against cancer induction. ${ }^{\left({ }^{(0-53)}\right.}$ For example, oral coumarin had resulted in regression of tumor induction, as reported by Baskaran et al (2012). They induced oral carcinomas in the buccal pouch of Syrian golden hamsters, and noted $100 \%$ tumor formation with marked abnormalities in the biomarkers status in hamsters treated with DMBA alone. Oral administration of coumarin at a dose of $100 \mathrm{mg} / \mathrm{kg}$ body weight to DMBA-treated hamsters completely prevented tumor formation as well as restored the status of biochemical variables. The results suggest that the chemo-preventive effect of coumarin is probably due to its anti-lipid peroxidative potential and modulating effect on carcinogen detoxification agents in favor of the excretion of ultimate carcinogenic metabolites of DMBA. ${ }^{(50)}$

In conclusion, 6 weeks of DMBA painting resulted in irreversible genetic changes that did not resolve by the studied repair enzymes. So it can be proposed that TQ had resulted in regression of the carcinogenesis process through the following mechanisms. First: TQ as a potent antioxidant, ${ }^{(54)}$ that antagonizes the adverse effect resulting from elevated ROS levels due to carcinogenesis i.e. reduction of the intracellular ROS allowed the repair enzymes to fulfill their main target. Second: TQ through inactivation of the TNF-Nf- $x \mathrm{~B}$ pathway, and in turn induced p53 activation, i.e. stimulated apoptosis of malignant cells. Third: TQ has the ability to arrest cells at different phases of the cell cycle leading to growth inhibition, so allowing repair of mutated cells. ${ }^{(56)}$

\section{Conflict of interests:}

The author declared that there is no conflict of interest, regarding results of this work.

\section{Ethical considerations:}

The proposal was approved by the Research Ethics Committee (REC), Faculty of Dentistry, Sues Canal University, EGYPT on 21/1/2018 number 70. 


\section{REFERENCES}

1. Salley J J. Experimental carcinogenesis in the cheek pouch of the Syrian hamster. J Dent Res, 1954; 33(2): 253-262

2. Shklar G. Development of experimental oral carcinogenesis and its impact on current oral cancer research. J Dent Res, 1999; 78(12): 1768-1772.

3. El-Dakhakhny M, Hassan M, Abdel-Aziz G. Effect of thymoquinone and poly - thymoquinone on chemically-induced oral epithelial dysplasia (experimental study). (Part I). Intern J Acad Res, 2009; 1(2): 107-117.

4. El-Mansy M N, Hassan M M, Abou El-Nour K M, ElHosary W H. Treatment of oral squamous cell carcinoma using thymoquinone loaded on gold nanoparticles. Proc. ICNA-III,. 2016: Hughada, Egypt.

5. Pitot H C, Dragan Y P. Facts and theories concerning the mechanisms of carcinogenesis. FASEB J, 1991; 5(9): 2280-2286.

6. Kumar M, Nanavati R, Modi TG, Dobariya C. Oral cancer: Etiology and risk factors: A review. J Can Res Ther, 2016;12 (2):458-463

7. Estrela J M, Mena S, Obrador E, Benlloch M, Castellano G, Salvador R, Dellinger R W. Polyphenolic phytochemicals in cancer prevention and therapy: Bioavailability versus bioefficacy. J Med Chem, 2017; 60(23): 9413-9436.

8. Gali-Muhtasib H, Roessner A, Schneider-Stock R. Thymoquinone: A promising anti-cancer drug from natural sources. Int J Biochem Cell Biol, 2006; 38(8): 1249-1253.

9. Gali-Muhtasib H, Diab-Assaf M, Boltze C, Al-Hmaira J, Hartig R, Roessner A, Schneider-Stock R. Thymoquinone extracted from black seed triggers apoptotic cell death in human colorectal cancer cells via a p53-dependent mechanism. Int J Oncol, 2004; 25(4): 857-866.

10. Schneider-Stock R, Fakhoury I H, Zaki A M, El-Baba C O, Gali-Muhtasib H U. Thymoquinone: fifty years of success in the battle against cancer models. Drug Discov Today, 2014; 19(1): 18-30.

11. Shoieb A M, Elgayyar M, Dudrick P S, Bell J L, Tithof P $\mathrm{K}$. In vitro inhibition of growth and induction of apoptosis in cancer cell lines by thymoquinone. Int J Oncol, 2003; 22(1): 107-113.

12. El-Dakhakhny M., Studies on the Egyptian Nigella sativa L. IV. Some pharmacological properties of the seeds' active principle in comparison to its dihydro compound and its polymer. Arzneimittelforschung, 1965. 15(10): p. 1227-1229.
13. Mansour M A, Nagi M N, El-Khatib A S, Al-Bekairi A M. Effects of thymoquinone on antioxidant enzyme activities, lipid peroxidation and DT-diaphorase in different tissues of mice: a possible mechanism of action. Cell Biochem Funct, 2002; 20(2): 143-151

14. Shata M S, Hassan M M, Abou El-Nour K M, El-Azab M F. Nano-chemoprevention of oral squamous cell carcinoma using thymoquinone loaded on gold nanoparticles. Proc. ICNA-III. 2016: Hurghada, Egypt.

15. Swidan S, Hassan M M A, El-Hossary W H. Chemopreventive effect of different doses of nanothymoquinone on chemically - induced oral carcinogenesis. MSc thesis, Suez Canal University: Ismailia. EGYPT, 2016

16. Algharyni HM, El-Hossary WHH, Korraah AMM, Hassan MMA. Expression of MyoD in the DMBA-treated hamster pouches following thymoquinone injection.. IOSR JDMS, 2019; 18 (4): 35-40

17. Hussain S P, Hofseth L J, Harris C C. Radical causes of cancer. Nat Rev Cancer, 2003; 3(4): 276-285.

18. Hoesel B, Schmid JA. The complexity of NF- $x$ B signaling in inflammation and cancer. Mol Cancer. 2013 Aug 2;12:86. doi: 10.1186/1476-4598-12-86.

19. Lindahl T, Barnes D E. Repair of endogenous DNA damage. Cold Spring Harb Symp Quant Biol, 2000; 65: 127133.

20. Stracker T H, Usui T, Petrini J H. Taking the time to make important decisions: the checkpoint effector kinases Chk1 and Chk2 and the DNA damage response. DNA Repair (Amst), 2009; 8(9): 1047-1054.

21. Zhou B B, Elledge S J. The DNA damage response: putting checkpoints in perspective. Nature, 2000; 408(6811): 433-439.

22. Abdel-Rahman W M. Genomic instability and carcinogenesis: an update. Curr Genomics, 2008; 9(8): 535-541.

23. Kowalski M, Przybylowska K, Rusin P, Olszewski J, Morawiec-Sztandera A, Bielecka-Kowalska A, Pietruszewska W, Mlynarski W, Janusz S, Majsterek I. Genetic polymorphisms in DNA base excision repair gene XRCC1 and the risk of squamous cell carcinoma of the head and neck. J Exp Clin Cancer Res, 2009; 28: 37-44.

24. Wang Y, Spitz M R, Lee J J, Huang M, Lippman S M, Wu $\mathrm{X}$.Nucleotide excision repair pathway genes and oral premalignant lesions. Clin Cancer Res, 2007; 13(12): 37533758 . 
25. An J, Liu Z, Hu Z, Li G, Wang L E, Sturgis E M, El-Naggar A K, Spitz M R, Wei Q. Potentially functional single nucleotide polymorphisms in the core nucleotide excision repair genes and risk of squamous cell carcinoma of the head and neck. Ca Epidemiol Biomar Prev, 2007; 16(8): 1633-1638.

26. Shuck S C, Short E A, Turchi J J. Eukaryotic nucleotide excision repair: from understanding mechanisms to influencing biology. Cell Res, 2008; 18(1): 64-72.

27. Sakano S, Ogawan S, Yamamoto Y, Nishijima J, Miyachika Y, Matsumoto H, Hara T, Matsuyama H. Ercc1 and Xrcc1 expression predicts survival in bladder cancer patients receiving combined trimodality therapy. Molec Clin Onc, 2013; 1: 403-410

28. Ratnasinghe D, Yao S-X, Tangrea JA, Qiao Y-L, Andersen MR, Barrett MJ, Carol A. Giffen CA, Erozan Y, Tockman MS, Taylor PR. Polymorphisms of the DNA repair gene $\mathrm{XRCC} 1$ and lung cancer risk. Cancer Epidemiology, Biomarkers \& Prevention, 2001;10: 119-123

29. Metzger R, Bollschweiler E, Hölscher AH, Warnecke-Eberz U: ERCC1: impact in multimodality treatment of upper gastrointestinal cancer. Future Oncol, 2010; 6: 1735-1749

30. Mahjabeen I, Ali K, Zhou X, Kayani MA. Deregulation of base excision repair gene expression and enhanced proliferation in head and neck squamous cell carcinoma. Tumour Biol 2014; 1: 5971-5983.

31. Curioni O A, de Carvalho M B, Dedivitis R A, Rapoport A, Gattas G J F. The influence of gene polymorphisms on tobacco and alcohol-induced oral cancer risk. J Ca Ther, 2013; 4: 978-988.

32. Ahmad A, Robinson A R, Duensing A, van Drunen E, Beverloo H B, Weisberg D B, Hasty P, Hoeijmakers J H, Niedernhofer L J. ERCC1-XPF endonuclease facilitates DNA double-strand break repair. Mol Cell Biol, 2008; 28(16): 5082-5092.

33. Mohrenweiser HW1, Carrano AV, Fertitta A, Perry B, Thompson LH, Tucker JD, Weber CA. Refined mapping of the three DNA repair genes, ERCC1, ERCC2, and XRCC1, on human chromosome 19. Cytogenet Cell Genet, 1989; 52: 11-14

34. Tebbs R S, Flannery M L, Meneses J J, Hartmann A, Tucker J D, Thompson L H, Cleaver J E, Pedersen R A. Requirement for the Xrcc1 DNA base excision repair gene during early mouse development. Dev Biol, 1999; 208(2): 513-529.

35. Sporn MB. Approaches to prevention of epithelial cancer during the preneoplastic period. CA RES, 1976; 36: 2699-2702.
36. Hoeijmakers J H. DNA damage, aging, and cancer. N Engl J Med, 2009; 361(15): 1475-1485.

37. Grawish M, Zaher AR, Gaafar AI, Nasef WA. DNA adduct formation by 7,12-dimethylbenz(a)anthracene in Syrian hamster cheek pouch epithelium in vivo. Ca Res, 1988, 48(8):2025-2028 .

38. Sun Z, Sood S, Li N, Yang P, Newman R A, Yang C S, Chen X. Chemoprevention of 7,12-dimethylbenz[a]anthracene (DMBA)-induced oral carcinogenesis in hamster cheek pouch by topical application of a dual inhibitor of epidermal growth factor receptor (EGFR) and ErbB2 tyrosine kinases. Oral Oncol, 2008; 44(7): 652-657.

39. Casto BC, Kresty LA, Kraly CL, Pearl DK, Knobloch TJ, Schut HA, Stoner GD, Mallery SR, Weghorst CM. Chemoprevention of oral cancer by black raspberries. Anticancer Res, 2002; 22; 4005-4016.

40. Vaezi A, Feldman $\mathrm{CH}$, Niedernhofer L J. ERCC1 and $\mathrm{XRCC} 1$ as biomarkers for lung and head and neck cancer. Pharm Pers Med, 2011; 4: 47-63.

41. Klaunig J E, Wang Z, Pu X, Zhou S. Oxidative stress and oxidative damage in chemical carcinogenesis. Toxicol Appl Pharmacol, 2011; 254(2): 86-99.

42. Shen MR, Zdzienicka MZ, Mohrenweiser H, Thompson LH, Thelen MP. Mutations in hamster single-strand break repair gene XRCC1 causing defective DNA repair. Nucl Acids Res, 1998; 26 (4): 1032-1037.

43. Basseres D S, Baldwin A S. Nuclear factor-kappa B and inhibitor of kappa B kinase pathways in oncogenic initiation and progression. Oncogene, 2006; 25(51): 6817-6830.

44. Abd El-Ghany L B, El Hossary W H, Hassan M M A. Expression of $\mathrm{P} 53$ protein following treatment of chemicallyinduced oral carcinoma by thymoquinone loaded on nanogold particles. (A retrospective study). Egy Dent J - July, 2018; 64: 1075-1081

45. Hassan MMA, Abdel-Latif A, El-Hossary W H. Protective and Promising Myogenic Effect of Two Thymoquinone Formulations in Relation to the Hamster Buccal PouchInduced Carcinogenic Model. IOSR Journal of Dental and Medical Sciences (IOSR-JDMS), 2017; 16(5): Ver. III, 54-66

46. Santana T, Sa MC, Santos EM, Galv ao HC, Coletta RD, Freitas RA. DNA base excision repair proteins APE-1 and XRCC-1 are overexpressed in oral tongue squamous cell carcinoma. J Oral Pathol Med, 2017; 46: 496-503 
47. El-Khamisy SF, Masutani M, Suzuki H, Caldecott KW. A requirement for PARP-1 for the assembly or stability of XRCC1 nuclear foci at sites of oxidative DNA damage. Nucleic Acids Res. 2003 Oct 1; 31(19): 5526-5533.

48. Amer MHI: Effect of different thymoquinone preparations on DNA repair enzymes in experimentally-induced oral cancer. Ph.D. thesis, Suez Canal University, EGYPT, 2018

49. Ding Y, Jiang Z, Saha K, Kim C S, Kim S T, Landis R F, Rotello V M. Gold nanoparticles for nucleic acid delivery. Mol Ther, 2014; 22(6): 1075-1083.

50. Baskaran N, Shanmugam M, Karthikeyan S, Prabhakar M M. Chemopreventive potential of coumarin in 7, 12-dimethylbenz[a] anthracene induced hamster buccal pouch carcinogenesis. Asia Pac J Cancer Prev (APJCP), 2012; 13(10):5273-5279

51. Uhrig LK. Feasibility of a long-term food-based prevention trial with black raspberries in a post-surgical oral cancer population: Adherence and modulation of biomarkers of DNA damage. Presented in Partial Fulfillment of the Requirements for the Degree Doctor of Philosophy in the Graduate School of The Ohio State University. The Ohio State University, 2014

52. Chen L, Zhang H Y. Cancer preventive mechanisms of the green tea polyphenol (-)-epigallocatechin-3-gallate. Molecules, 2007; 12(5): 946-957.

53. Al-Jawfi, K.A.M, Hassan, M.M.A, El-Gohary, A.M. Effect of Nigella sativa oil on the hamster lymphocytes secondary to DMBA-induced carcinogenesis. Suez Canal Med J., 2008; 11(1): 75-80.

54. Badary O A, Taha R A, Gamal el-Din A M, Abdel-Wahab $\mathrm{M} \mathrm{H}$. Thymoquinone is a potent superoxide anion scavenger. Drug Chem Toxicol, 2003; 26(2): 87-98.

55. Rania Hanafi and Rasha Taha. Immuno-Histochemical Study of the Potential Impact Effect of a Single Intra-Peritoneal Injection Dose of Cisplatin on Stem cells of Dental Pulp of Albino Rats. J Oral HealthDentSci, 2020; 4:303http://www. scholarenajournals.org/journals/journal-of-oral-health-anddental-science/articles.php? volume $=4 \&$ issue $=3$

56. Magda MA Hassan, Wafaa H El-Hossary, and Rania Hanafi. Anti-inflammatory Thymoquinone and Muscle Regeneration in the Hamster Buccal Pouch-Induced Dysplsia.J Oral Health Dent Sci, 2020; 4:302

57. Kaczmarek E.A. Goma and Majewski P. Techniques of image analysis for quantitative immunohistochemistry. Rocz Akad Med. Bialyms, 2004t; 49(1):155-158. 